\title{
AC 2009-2515: MAKING OF A GLOBAL ENGINEER: CULTURE AND TECHNOLOGY
}

\section{Aparajita Mazumder, Formerly Director of International Relations}

Dr.Aparajita Mazumder has both educational and life experience in international studies. She received her PhD in Comparative Literature (1990) from the University of Illinois at Urbana-Champaign,USA. Specializing in cross-cultural studies, she devoted her professional career to directing, developing and administering global engineering education. She was the first Director of International Programs in Engineering at the University of Illinois at Urbana-Champaign and the Director of International Relations and Education at the University of Michigan. 


\title{
Making of a Global Engineer: Culture and Technology
}

\begin{abstract}
"Making of a global engineer" interfaces culture and technology. With the operation of technology on a global scale, comes the question of dealing with the complex dynamics of a global professional environment where world languages, cultures, educational and technical systems meet. This leads to the conclusion that technology and cross-cultural issues are intrinsically entwined in global engineering. What kind of specialized skills do we need to enable the crossing of different cultures and world systems with ease? Can we create a global engineer with both technical and cross-cultural skills through an educational system? What are the curriculum resources available in engineering education for creating the cultural competent technologist?

This paper examines the interfacing of technology and culture in the global environment and shows the vital link between global technology and global culture. It touches on issues such as the meaning of culture, differences and commonality, verbal and non-verbal communication, differences in negotiation styles, cultural adaptation and integration, and phenomenon of crosscultural refraction. It explores selective educational models for integrating global cultural education into the engineering curriculum. These selective models: concentrations and minors, cultural courses and cultural components in dual degree and simultaneous degree programs, global simulation projects, international internships and team projects, study abroad and global courses provide valuable information on different educational models currently in place in institutions.

International leadership whether it be in academia, industry or government calls for motivation of a workforce coming from diverse academic, linguistic and cultural backgrounds. "Making of a global engineer," is a valuable tool for the global technical enterprise. It explores the twin questions of "why?" cross-cultural education is vital for the global engineer and shows "how?" to attain this education through an educational process. It tries to provide a direction to follow.
\end{abstract}

\section{Introduction}

The interfacing of culture and technology dramatically unfolds when we take a close look at international ventures in academia, industry or government. For illustrative purpose here are a few examples. Take the international space station venture as an example, which combines the resources and technological expertise of more than thirteen cooperating nations that include United States, Denmark, France, Italy, Netherlands, Norway, Spain, Brazil, Russia, Japan, United Kingdom, Switzerland and Sweden. The Russian team worked on the Soyuz capsule, USA on the Destiny lab, the European Space Agency on the Autonomous Transfer Vehicle, the Japanese on the Japanese Experiment Module, and the Brazilians on the Window Observational Research facility. The challenge of a global venture of this scale requires not only technical knowledge,but also global understanding and capacity forinternational teamwork. Chevron oil company's initiatives to construct gas pipelines, take us to company projects in the Caspian Sea, the Russian Black Sea, Nigeria, Benin, Togo, Ghana, South America and Thailand.The necessity for regional and cultural understanding and at times linguistic knowledge is apparent when we 
visualize foreign and native executives in distant locations working alongside. A Siemens marketing brochure follows a Scandinavian Airport project from beginning to end. Through a single assignment we travel through different time zones, negotiating with different races in Hong Kong, Penang and Germany,meeting global teams from different countries, interacting with colleagues from different background and adjusting to different work environments. From these few examples we see the vital link between technology and culture and realize the necessity of learning to communicate across cultures when in a global engineering environment.

\section{Culture and Technology}

What is Culture? The word has its roots in the Latin word "cultura" meaning cultivation. There is a wide range of perspectives on culture ranging from the concrete (clothes, music food), to behavioral (language, gender roles) and symbolic (value system, customs, religion). Cultural value is seen as "a collective programming of the mind which distinguishes the members of one human group from another" (Hofstede, 1984. P. 21). It is a way of life or a shared thinking pattern of a race. In a corporate or technical community, culture may be viewed as a set of rules for behavior, thought and feeling which is widely shared by the members of the corporate/academic/technical community. Clark and Kulacki in "International Engineering: Things your Engineering School Never Told You," illustrates how different cultures have different values through two common sayings. The Western saying, "the squeaky wheel gets the grease" goes back to Roman times. The Eastern saying, "The nail that sticks up gets hammered down," goes back to Confucian time. "Despite our simplicity here, these philosophies create radically different values in group situations and how people relate to each other." No doubt an engineer, "the squeaky wheel" used to being rewarded for standing out for his individual voice will find it difficult to function effectively in an environment where the group voice is rewarded. This simple example indicates that it is essential for the technologist to have knowledge of the group-thinking pattern when in global interaction. Education on the following areas will lead to a deeper understanding of cross-cultural interactions.

\section{Differences and Commonality}

World customs vary and these permeate the engineering work environment. Take a simple object as a paper as an example. Same objects are regarded differently.In Japan, the "meishi" or the business card is treated with great respect, as it is a symbol of the person it represents. Hindus who believe that the Goddess of Knowledge, Saraswati is embodied in a paper may do a "namaste" as a sign of apology if by accident they step on a paper. A typical business lunch in USA may involve networking, brainstorming, agendas, audio-visuals and more. A Mexican business lunch on the other hand, may have a more leisurely pace and end with the saying "Mi casa es su casa," promising friendship, honesty and fair dealing. You may be offered a "squash" at a business meeting in Kolkata and refuse politely when what you were being offered is a freshly squeezed glass of orange juice andnot vegetables. Or accept "fruits de mer" in France thinking fruits will be served and have "shellfish" brought to you. If we look at the educational backgrounds of people who make up a global team you may find differences in degree durations, timing when a particular material is taught, grading systems, teaching and learning styles and terms used for even degrees earned (Haksa, Vordiplom, Kandidat. Ptychion, Licenciado, Oklevel, Bachelors). A global skill that will no doubt enhance performance for the technologist is to be aware of differences and commonality, which might be subtler than the earlier squeaky wheel and nail examples from the West and the East. 


\section{Verbal and Non-Verbal Communication}

Kohls and Knight describes intercultural communication as being "a process by which two individuals who do not belong to the same culture tryto exchange a set of ideas, feelings, symbols....meanings." Since they do not belong to the same culture, it implies that they do not share the same assumptions, beliefs, values or...some ways of thinking, feeling, behaving. This phenomenon makes the communication process much more difficult and challenging than we think" (Developing Intercultural Awareness, p. 59). In intercultural situations there is the verbal challenge-differences in meaning, language, pronunciation, accent, voice and the non-verbal, body language, gestures, facial expressions, physical appearance and artifacts, space, touch. Can the same non-verbal aspect have a different meaning in another culture? If we take silence and eye contact as examples; silence is an opportunity to formulate a carefully thought out response in some cultures, whereas silence is considered to be awkward in the West. Eye contact in many cultures is considered to show defiance and eyes are quickly shifted away.In the West, it is an act of confidence and sincerity. Similarly with space, some cultures prefer standing close, whereas others prefer a distance. In cross-cultural encounters, the translation of the non-verbal is as important as the verbal.

\section{Differences in Negotiation styles}

Language, physicalappearance, business etiquette, a different style of negotiating may separate negotiators. Americans value discussions and have a leadership style where managers take the lead and delegate to subordinates. In the "Rice-Paper Ceiling: Breaking through Japanese Corporate Culture," Kopp observes that for the Japanese, openly challenging another's opinion at a meeting is viewed negatively and "decision making is a group process where large numbers of people are involved in each decision."Seniority is respected in the East and often the leader is the older person to whom proper respect has to be shown. To the French, "protocol, manners, status, education, family, and individual accomplishments" are important. Negotiating teams with a majority of membersas women might be at a disadvantage in a culture where women still do not hold equal status in the business world. Often, the success/failure of many business and technological ventures may be determined by the ability/inability to overcome cultural differences. In "Cross-Cultural Business Negotiations," Hendon et al writes: The way one succeeds in cross-cultural negotiations is by fully understanding others, using that understanding to one's own advantages to realize what each party wants from the negotiations, and to turn the negotiations into a win-win situation from both sides." Kale in "Universal Code of Ethics in Intercultural Communication" describes the ethical communicator as one "who address people of other cultures with the same respect that they would like to receive" and as one "who encourages people of other cultures to express themselves in their uniqueness." The ideal communicator is in essence one who has mastered the art of diplomacy and can relate to a particular culture and communicate in a diplomatic way to achieve an end.

\section{Cultural Adaptation and Integration}

Bennett in "A Developmental Approach to Training Intercultural Sensitivity" presents two states when confronted with difference. In the Ethnocentric state there is a tendency of denial of difference, defense against difference and minimization of difference. In the Ethno relative stage there is acceptance, adaptation and integration of difference. Bennett explains how this stage can be reached: 
Acceptance of Difference: Recognition and appreciation of cultural differences in behavior and values will lead to an acceptance of differences.

Adaptation of Differences: Development of communication skills enabling intercultural communication and effective use of empathy or shifting frame of references between cultures in order to understand and be understood across cultural boundaries will lead to adaptation of differences.

Integration of Differences: Internalization of bi-cultural and multicultural frames of reference.

When we think of cultural differences, we must remember there areuniversal values that act as a unifying force-trust, love, friendship, fear, hospitality, and honesty. Storti believes in Art of Crossing Cultures that "if encounters stays within the range of universal behavior (human nature) then no cultural difference will arise."

\section{Cross-Cultural Refraction}

Harry Levin in Refractionscites the following definition of "refraction" from the Shorter OxfordDictionary: Refraction...is the fact or phenomenon of a ray of light, heat, the sight, etc. being diverted or deflected from its previous course in passing obliquely out of one medium into another of different density, or in traversing a medium not of uniform density (ix-x). Levin applies this term to cross-cultural encounters making the medium responsible for the degree of change.

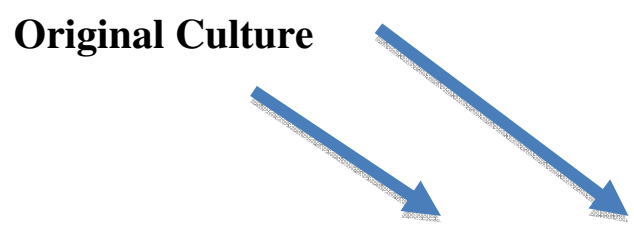

Entering Foreign Culture (Medium of Refraction)

\section{Refractions in Cultural Perception}

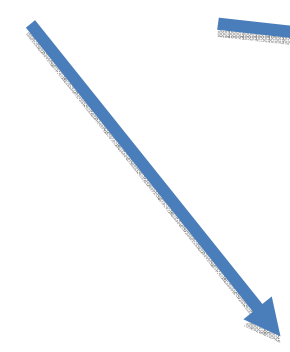

When cultures/different systems meet, a phenomenon of change occurs and the many directions the changes take are termed as cross-cultural refractions.During an engineers journey across cultural boundaries changes occur in the perception of language, culture, education, technology and global philosophy.

\section{Global Educational Models}

What kind of specialized skills do we need to enable the crossing of different cultures and world systems with ease? Useful global tools to increase intercultural competence are: 
- Developing ability to adapt to different work environments through global team experience and education

- Learning educational systems of other nations

- Mastering foreign language and communicating across cultures

- Cultivating knowledge of "group thinking pattern" and "learned body of tradition."

- Having an insight into differences and commonality in customs, negotiation styles, communication styles

- Learning the art of diplomacy.

Can we equip engineers with these global tools to increase intercultural competence through an educational system? What are the curriculum resources available in engineering education for creating the cultural competent technologist? When we think of curriculum resources, a rich resource for cultural education is there in cultural pockets such as little Italy, Devon Street in Chicago, China Town in San Francisco and Greek Town in Detroit. There are exchange and international students and scientists that can act as resources for cultural education in many institutions. The educational foundation is there for combining technology with culture in the engineering curriculum. These selective models: concentrations and minors, cultural courses and cultural components in dual degree and simultaneous degree programs, global simulation projects, international internships and team projects, study abroad and global courses are different educational models currently in place in institutions.

\section{Cross-Cultural Education through International Minors and Concentrations}

An International Minor in Engineering is a concentrated effort to include international studies into the four-yearengineering curriculum. This is donethrough selection of global courses to fulfill humanities, social science, and free elective and at times technical elective requirements. Regional expertise is built through a focused approach. For example, an International Minor can be earned with a focus on Latin America, Middle East, or Japan. The requirement for the University of Illinois at Urbana-Champaign's Minor is a total of 21 credit hours of course work with the condition that a 300 level political and economics course in the region of focus be included and only 12 of the credits be used for language study. Astudy or work abroad experience is part of the requirement. For example, a student pursuing a Minor with a Japan focus may take elementary, intermediate, intensive, or advanced Japanese to build language capacity, take cultural courses offered by Liberal Arts Departments such as Japanese Culture, Japanese Art, Japanese Economy (300 level), and study at Nagoya university or intern at Toyota in Japan to fulfill the overseas experiential study requirement. The credit hour requirements may vary in different institutions. The University of Michigan's Program in Global Engineering, which again combines course work with overseas experience,requires 24 credit hours of course work. The total credit hours comprises of a required 2 credit hour course on cross-cultural understanding, 8 credit hours of language study, 8 credit hours of 300 level courses and 6 credit hours of free elective courses. Global courses are selected for their global content from the home institution and abroad. The cross-cultural course is specially designed for the technological 
student. It teaches aspects of globalization of technology, art of learning from another culture and different business and educational systems. The global work experience requirement provides the invaluable experiential learning experience. This is a flexible framework where the technologist with cultural experience graduates within four years with the Minor or Concentration recordedin the transcript.

\section{Cross-Cultural Education through Dual/Simultaneous Degree Programs}

As the term Dual degree and Simultaneous degree implies, two degrees are awarded and this lengthens the engineering curriculum to five years or more. University of Connecticut's EUROTECH program is a five-year program with a B.S. in Engineering and a B.A. in German. To make a degree in German beneficial for the engineer, the German curriculum was redesigned to include special purpose and interdisciplinary courses such as 1 credit modules conducted in German on engineering topics. A few faculties with German proficiency from the School of Engineering was recruited for this purpose, German speaking scientists were invited as guest speakers to speak on topics ranging from electron-beam welding to energy. German professors and exchange students provided assistance for the understanding of German technical terms. For the six-credit internship program to provide the essential intercultural professional experience with German professionals, internships were arranged in German firms in USA and Germany (Reference is from the EUROTECH handbook).

University of Rhode Island's Dual Degree program offers two degrees. One of them is from the US university, and the other from the foreign university in Germany, France, or Spain. Sufficient language proficiency is required to do course work in the foreign institute. US engineering students complete half of their Masters program at Rhode Island and spend the second year at the foreign university (e.g.Technische Universitat Braunschweig) as a full time student. The European students enroll as full time students at Rhode Island when they are within one year of receiving their degree from their home institution. The study abroad year involves course and thesis work and is closely coordinated by faculty at both institutions thus enabling students to complete degree requirements in Rhode Island and the European institute. In-depth exposure to language and culture and engineering education and practice other than their own is attained through this program

University of Michigan's Engineering Global Leadership Honors Program, which awards an Undergraduate and a Masters degree, has a technical, business and cultural core with a team project.Designed to train engineers to excel in technology and to bridge cultures, the cultural core utilizes 12 credits of the 20 credit Humanities and Social Science requirements to focus on language, history, economics and politics of a particular region in East Asia, Eastern Europe, Middle East, Latin America, South Asia, Southeast Asia or Western Europe. Two years of language study is a requirement. Courses are generally taken in the College of Literature, Science and Arts or in a study abroad program in the selected region. The industry team project when international with a multicultural team, provide experience of working with global team members.

\section{Cross-Cultural EducationCourses}

Area study centers, departments such as Slavic studies, French, German, Linguistic studies, Religious studies, Comparative Literature, Business, Law, Political Science and Economics all 
act as resources to draw upon when selecting courses for cross-cultural and global training. There are a wide variety of courses to choose from. However, we shall look at a few selected models beneficial for the technical student.

Simulation Games: A simulation game which dramatically illustrates differences in cultural values andits impact on negotiations is a game named " $\mathrm{BaFa} \mathrm{BaFa"} \mathrm{created} \mathrm{by} \mathrm{R}$. Gary Shirts in 1977. This game can be used effectively as an "Icebreaker" in any classroom to bring an immediate awareness to technical students of the importance of cross-cultural studies. In this game, negotiators from a Beta culture use a style that is collective, formal, patient, indirect, unemotional and passive. The alpha negotiators use an opposing style that is individualistic, informal, direct, emotional and aggressive. Example:

Collectively: Loyalty to the group takes precedence over personal feelings. Use the word "we" not "I". Any decision by your side must be reached by group consensus. If you cannot agree then defer the decision.

Indirectly: Ask many questions, while offering little information. Betans are tentative, vague and play hard to read.

No doubt, when playing this game, the negotiation process between beta and alpha teamswill be long and difficult as each team tries to come to term with the other team's style of negotiation.

Another example of a simulation game to develop multicultural skills is a simulation course “GLOBETECH International Technology Management Computer Simulation” program developed at Cooper Union in 1995. The simulation took place with two teams from Cooper Union, one representing a Chinese company interested in a car manufacturing joint venture, the other representing Toyota Motor Co. The focus of the simulation was on international negotiations necessary to establish the joint venture between the Chinese and the Japanese companies. The teams discussed via computer the current economic developments in China, the specifics of the automobile industry in the country, the competitive pressure facing international car manufacturers wanting to invest in China and current technology management issues.

Many institutions have designed global courses for engineers. University of Illinois offers a series of regional specific preparatory courses as pre-departure courses for Study Abroad. University of Michigan's Program in Global Engineering's two credit hour cross-cultural course interfacing culture and technology covered five main topics:

A) Globalization of Technology: Academic/Industrial/Government Perspectives

B) Culture, Academic, Business Practice of a Region (e.g. Mexico, China)

C) US Cultural Values

D) Crossing Cultures and Cultural Refractions

E) Global Engineering and Art of learning from another culture 
The global engineering environment, cross-cultural issues when working internationally, differences in work environment, phenomenon of change or refraction when crossing cultures, is some of the topics discussed in a classroom setting.Another example of a course specially designed for the technologist, is a Global Perspective in Technology Management course developed at Cooper Union (described in ASME conference proceedings in 1997). The one term course through fifteen sessions explored technological strengths/weaknesses of various industrialized emerging economies, role of customs and traditions in succeeding in business, international industrial collaborations, intellectual property issues in global technology related trade and international quality control and international business negotiations.

Some institutions are making effective use of distance learning to create avirtual classroombringingstudents, laboratories, white boards to the other side of the globe. This is a new direction in global education practice that can be used effectively to build international competency. The emergence of the global classroom is apparent in the Global Product Realization course offered simultaneously via satellite initially to students in the Netherlands, at Delft Institute of Technology, in Korea, at Seoul National University,and at the University of Michigan in 2000 (refer to Michigan Engineer, Spring/Summer 2001, article on "Going Global," pgs. 4-5).Time zone differences were accommodated with the class meeting at 8 am in Michigan, 2pm in the Netherlands, and $10 \mathrm{pm}$ in South Korea on the same day. A multicultural team worked on a team project together through distance learning. This gave them a fore taste of what it would be like to work with colleagues living in different cultures, each accustomed to their own educational systems and each fluent in their own language, but communicating in English. While the technical aspect is important, the valuable lesson of learning to cooperate through distance cannot be undermined.

\section{Cross-Cultural Education through Study Abroad and International Team Projects}

Study abroad can be a group study tour, a summer program,and a semester or academic year program. Typically, 6 to 9 credits are transferred for a summer program, and 12 to 16 credits for a semester or academic year program with institutional approval.

A Study tour of two or three weeks acts like a discovery experience exposingstudents to a different country, culture and language. It involves visits to different industries and academic institutions in that country to introduce students to existing industrial ventures, engineering practice and education in that country.It is a prelude to a longer period of immersion in academia or industry in that region at a later time. An example is "Engineering 4060: Study Abroad" offered by the College of Engineering, Technology and Architecture at Oklahoma State University in Italy, France, Brazil, China, Japan and Spain. Technology is combined with culture in these technical and cultural tours lasting a fortnight. In France, exposure to wine production in Avignon and nuclear plants in Toulouse, is combined with experiencing art and architecture in Louvre and Versailles. In Brazil, a tour of the world's largest hydroelectric dam at Iguassu Falls, renewable energy companies at Londrina andsugarcane refinery at Sao Paulo is combined with visits to native villages.

Summer programs designed for engineers, typically combine language and cultural studies with industrial experience. Cultural courses may be taught in the mornings with industrial internships in the afternoons. Students attending a summer program in Germany, may focus on learning the 
German language in the morning and work at a Porsche plant or a German laboratory in the afternoon. In Australia, the University of New South Wales, "Energy Beyond 2000: An Engineering and Management Perspective," focuses on worldwide energy issues such as Energy Management, World Energy, Environmental Implications and Alternative Sources of Energy. The course is offered at different sites in Australia-Darwin, Sydney, New South Wales, and Queensland. Multiple locations give students an opportunity to learn about the land, people and culture through travel. Semester and academic year study abroad involves taking courses at a foreign university with institutional approval to enable transfer of credit. Technical courses can be combined with social science, humanities and free elective courses.

International Team Projects and Work Abroad opportunities provide an environment where world languages, cultures, educational and technical systems meet. Work Abroad can be arranged through organizations such as International Association for the Exchange of Students for Technical Experience (IAESTE) and L'Association Internationale des Etudiants en Sciences Economiques et Commercial (AIESEC) or through direct arrangements with companies at international locations. Many engineering institutions now award credit for international projects. Worcester Polytechnic Institute's global team projects success can be linked to giving students an opportunity of fulfilling academic degree requirements for formal projects such as "Interactive Qualifying Project (IQP)" which relates science and technology to societal concerns on or off campus.

Education in an international institution, laboratory or industry, studying /working alongside global teams of scientists, engineers, industrialists, fellow students, transforms "an engineer" into "a global engineer."Through the years, students have voiced how international projects have developed their global skill sets and how they "grew as engineers." In Chile, a University of Illinois Civil Engineering student as early as 1993 with team members from Centro de Asistencia Tecnica (CAT) made a trip to an open pit copper mine in Copiapo. He was working alongside Chileans pouring concrete cylinders and conducting slump tests and at the same time experiencing a joint venture between Bektel and the Chilean government. To him, it was a lesson in life that taught him, "how to accept another way of doing and seeing things." At Siemens Variable Drives, Joel Hartter a University of Michigan double major in Mechanical Engineering and German, worked in the area of product testing, design and production planning in the main facility that produced electric motors. While advancing his engineering skills, he learnt valuable global skills of adaptation, integration and intercultural communication. "I understand what it takes to function abroad, adapt to another culture and communicate my ideas."Self-discovery is an important experience in overseas experiential learning experience. The new confidence in proving that you can productively function in another culture, the inexplicable maturing that occurs in placing yourself in a new situation and a realization of your place in this diverse universe are some aspects. Cross-cultural refractions occur in perceptions of culture and technology as they confront different technological systems, different thinking processes, and different business practices. Change is an essential factor-whether it is a broadening of perception, adapting to a diverse workforce or realizing the importance of becoming a global engineer.

\section{Conclusion and Recommendations}

The global educational models explored in this paper, ranging from classroom simulation projects to dual degrees and distance learning, are curriculum resources available for global 
education.Global skills we found that can be attained through these educational models is summarized in the following "global skill toolbox."

\section{GLOBAL SKILL TOOL BOX}

- Foreign language capability and insight into communication style

- Knowledge of culture, customs, social behavioral and group thinking pattern of a region

(E.g. differences and commonality, verbal-non-verbal communication, differences in negotiation styles)

- Knowledge of global technology, foreign education system, and business practice

- Capacity toaccept, adapt and integrate other cultures. Bridging the difference

- Awareness of the phenomenon of cross-cultural refraction as an essential result of crossing cultures.

- Self knowledge and knowledge of technology and culture of your own country.

- Knowing that it is alright to seek a "cultural oasis" in a foreign country where you rest upon your own culture

- Learning the art of diplomacy in intercultural communication

- Ability to work on projects with multicultural teams face-to-face and through distance

- Ability to use all the computer and state of the art technology that makes this world an interconnected world

- Seeing oneself as a part of this diverse universe-a world person

Equipped with a tool- box of skills, the global engineer is ready for the assignment in the International Space Station, a Chevron project far away in the Caspian Sea, or a Scandinavian Airport project.

In conclusion, in view of the intrinsic link between technology and culture, it is recommended that engineering institutions provide cross-cultural education to engineering students:

1. By encouraging foreign language study.

2. By developing a "Culture and Technology" course designed specifically for the engineer, or by developing a cultural core in a degree program (e.g. University of Michigan's Engineering Global Leadership Honors Program).

3. By effectively utilizing humanities, social science and free elective requirements to create an International Minor to provide comprehensive global education and build regional expertise.

4. By developing study tours, international team projects, summer/semester/academic year study abroad and international internships for international experiential learning opportunities.

5. By having opportunities for the novice as well as the advanced student capable of a Dual degree program so that all students can participate in the process of attaining crosscultural education. 
"Making of a Global Engineer" is an educational process that can be taught and learnt through global educational models. By developing the vital skills summarized in the "global tool-box of skills"the global engineer can be an effective player in today's environment where world technology and cultures meet in seconds through cyber space.

\section{Bibliography}

1. Archer, Dane, Unspoken Diversity: Cultural Differences in Gestures, Qualitative Sociology, 20 (1) 79-105 (Spring 1997).

2. Bennett, M.J. A Developmental approach to training for intercultural sensitivity, International Journal of Intercultural Relations (1986).

3. Conference Proceedings: Mechanical Engineering Education for Global Practice. ASME Mechanical Engineering Conference (1997).

4. Directory of American Firms operating in foreign countries, Vols. 1,2.3, New York: Uniworld Business Publications, (1995).

5. Fowler, S.M. Two decades of using simulation games for cross-cultural training. Simulation and Gaming, 25 (4), pp. 464-476, 536-544, (1994).

6. Friedman, Thomas L. The World is Flat: A Brief History of the Twenty-First Century. New York: Farrar, Straus and Giroux, (2005).

7. Hendon, Donald W., Hendon Rebecca Angeles and Herbig Paul.Cross-Cultural Business Negotiations, Westport, Connecticut, London: Praeger Publishers (1999).

8. Hidalgo N. Multicultural teacher introspection in Perry T. and Fraser J. (eds.) Freedom's Plow: Teaching in the Multicultural Classroom, Routledge: New York (1993).

9. Hofstede Geert H. Culture Consequences: International Differences in Work-Related Values, abridged edn. Thousands Oaks CA: Sage Publication Inc. McGraw Hill (1984).

10. Hofstede and Pedersen. Exploring Culture: Excersises, Stories and Synthetic Cultures, Intercultural Press (2002).

11. Kale, David. Intercultural Communications, Lecture 10 (http//www.interculcom.blogspot.com)

12. Kohls, Robert L. and Knight, John M. Developing Intercultural Awareness: A Cross-Cultural Training Handbook (1994).

13. Kunda, Gideon. Engineering Culture: Control and Commitment in a High-Tech Corporation, Philadelphia: Temple UP, (1992).

14. Levin, Harry. Refractions. New York: Oxford UP, (1966).

15. Mazumder, Aparajita. Making of a Global Engineer: Philosophy ad Practice, Bloomington, Indiana: Author House (2008).

16. Storti Craig.Art of Crossing Cultures, Intercultural Press (2001). 
17. Weichert D, Rauhut B., and Schmidt R. (eds.), Educating the Engineer for the $21^{\text {st }}$ century, 229-233, Kluwer Academic Publishers. Netherlands (2001).

18. Web Address: University of Connecticut: http://www.eng2.uconn.edu/EUROTECH

19. Web Address: University of Rhode Island:http://www.uri.edu/iep/german/overview

20. Web Address: University of Michigan: http://www.engin.umich.edu/egl/

21. Web Address: University of Illinois: http://www.rngineering.illinois.edu/international/minor/

22. Web Address: Cooper Union Globetech :

http://www.cooper.edu/engineering/projects/gateway/eid/global/GlobeTech-iii/ 


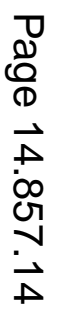

